\title{
Observation of the uranium 235 nuclear magnetic resonance signal $(*)$
}

\author{
H. Le Bail, C. Chachaty, P. Rigny and R. Bougon \\ Département de Physico-Chimie, CEN de Saclay, 91191 Gif-sur-Yvette Cedex, France
}

(Reçu le 26 septembre 1983, accepté le 20 octobre 1983)

\begin{abstract}
Résumé. - La première observation du signal de résonance magnétique nucléaire de l'isotope 235 de l'uranium est présentée. Elle a été effectuée sur l'hexafluorure d'uranium pur, à l'état liquide à $380 \mathrm{~K}$. Le rapport gyromagnétique mesuré est égal à $\left|\gamma\left({ }^{235} \mathrm{U}\right)\right|=492,6 \pm 0,2 \mathrm{rad} . \mathrm{s}^{-1} \mathrm{G}^{-1}$.

Abstract. - The first observation of the nuclear magnetic resonance of the uranium 235 is reported. It has been performed on pure liquid uranium hexafluoride at $380 \mathrm{~K}$. The measured magnetogyric ratio is $\left|\gamma\left({ }^{235} \mathrm{U}\right)\right|=492.6 \pm 0.2 \mathrm{rad} . \mathrm{s}^{-1} \mathrm{G}^{-1}$.
\end{abstract}

The uranium 235 magnetic moment $\mu_{\mathrm{N}}$ has previously been estimated only by indirect methods, the paramagnetic resonance of the $\mathrm{U}^{3+}$ ion inserted in a lanthanum chloride matrix $[1,2]$ and the optical absorption of the ${ }^{235} \mathrm{U}$ atom [2]. Both these methods indicate unambiguously that the nuclear spin is $I=7 / 2$, but they only provide the magnetic moment value through delicate assumptions about quantities like $\left\langle r^{-3}\right\rangle$, where $r$ is the electron spin to nuclear spin distance, the brackets corresponding to a quantum average of the relevant wave functions. The values of $\left|\mu_{\mathrm{N}}\right|$ deduced thereof are found between 0.31 and $0.35 \beta_{\mathrm{N}}, \beta_{\mathrm{N}}$ being the nuclear magneton. These values, among the smallest of the periodic table, correspond to a magnetogyric ratio of 424 to $479 \mathrm{rad} . \mathrm{s}^{-1} \mathrm{G}^{-1}$. The nuclear resonance frequency calculated from these values is between $1.58 \%$ and $1.79 \%$ that of the proton in the same magnetic field. On the other hand, the quadrupole moment of uranium 235 is very large, being estimated to 4.1 barns [1] or 6.4 barns [2]. Under these conditions, a very low sensitivity of detection is expected, explaining possibly why the NMR observation of this nucleus has not been reported before.

We report here the first NMR observation of ${ }^{235} \mathrm{U}$. The uranium hexafluoride has been chosen for these experiments because the quadrupole effects are minimized by its cubic symmetry in the liquid state. Pure liquid $\mathrm{UF}_{6}, 93.5 \%$ enriched in ${ }^{235} \mathrm{U}$, has been studied at $380 \mathrm{~K}$, in a $10 \mathrm{~mm}$ o.d., $6 \mathrm{~mm}$ i.d. sealed silica tube. At this temperature, the $\mathrm{UF}_{6}$ vapour pressure is ca. 4 bars.

The NMR spectra were recorded on a BRUKER WM 500 spectrometer with an external field of $11.747 \mathrm{~T}$. The rf. power corresponds to a $\Pi / 2$ pulse of $90 \mu \mathrm{s}$. On the figure are compared the absorption spectra of $\mathrm{UF}_{6} 93.5 \%$ enriched in ${ }^{235} \mathrm{U}(\mathrm{A})$, of $\mathrm{UF}_{6}$ with a natural abundance of $0.72 \%$ in this isotope (B) and an off resonance blank recording (C).

(*) La version française de cet article a été proposée aux Comptes Rendus de l'Académie des Sciences. 


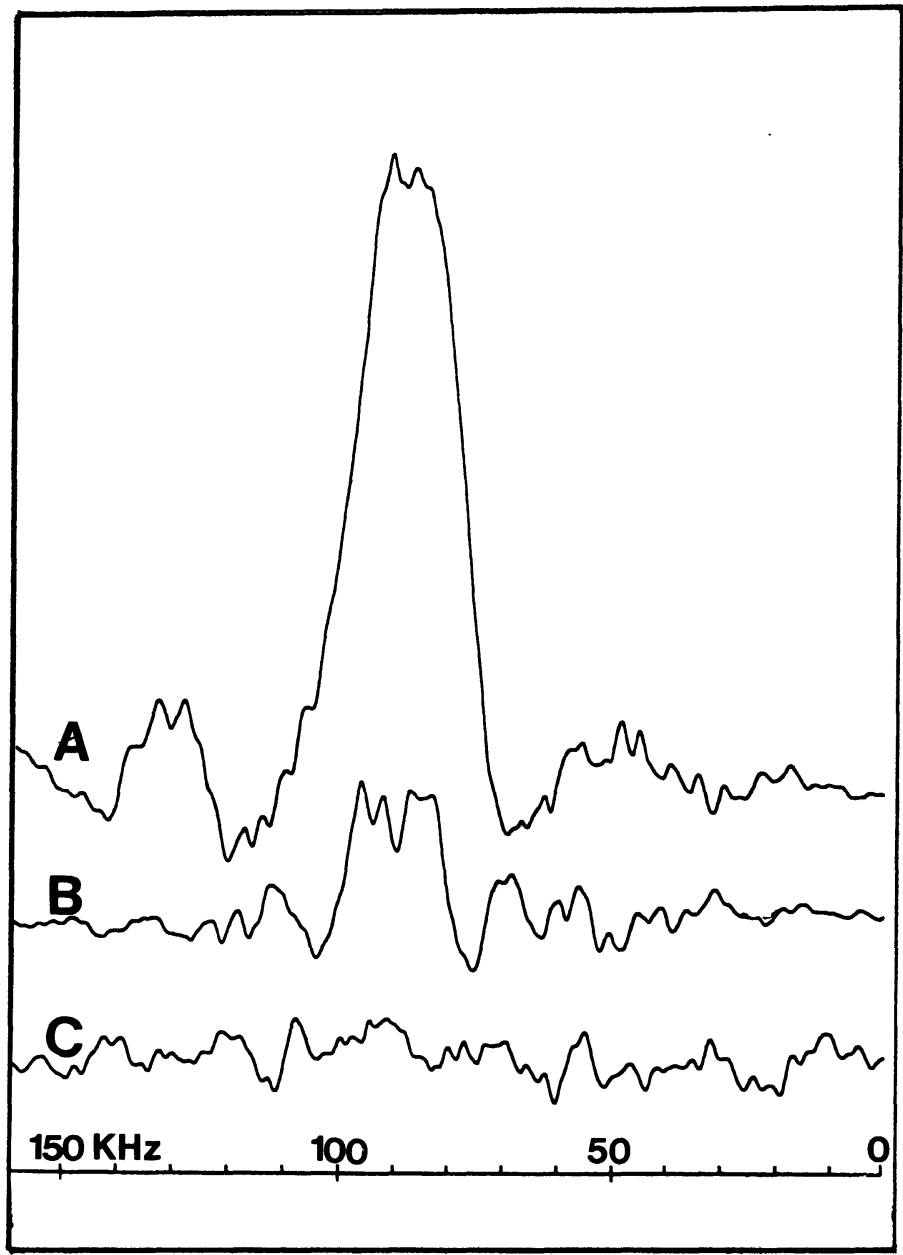

Fig. 1. - (A) NMR spectrum of $93.5 \%$ isotopically enriched ${ }^{235} \mathrm{UF}_{6}$, origin of the spectrum $9.126666 \mathrm{MHz}$. (B) Spectrum of natural $\mathrm{UF}_{6}$, same origin as (A). (C) Off resonance baseline, origin : $9.336666 \mathrm{MHz}$.

The measured resonance frequency of ${ }^{235} \mathrm{U}$ is $v=9.209_{8} \pm 0.004 \mathrm{MHz}$, corresponding therefore to a magnetogyric ratio :

$$
\left|\gamma\left({ }^{235} \mathrm{U}\right)\right|=\left(0.01841_{4} \pm 0.00001\right) \gamma_{\mathrm{H}}=492.6 \pm 0.2 \mathrm{rad} . \mathrm{s}^{-1} \mathrm{G}^{-1}
$$

$\gamma_{\mathrm{H}}$ being the proton magnetogyric ratio in tetramethylsilane $\left(26751 \mathrm{rad} . \mathrm{s}^{-1} \mathrm{G}^{-1}\right)$. The nuclear moment given by the expression $\left|\mu_{\mathrm{N}}\right|=\left|\gamma\left({ }^{235} \mathrm{U}\right)\right| \hbar I$ is thus equal to $0.3599_{9} \pm 0.00015_{\mathrm{r}} \mathrm{nu}-$ clear magnetons, with likely a negative sign according to reference 3 . The $\mu_{\mathrm{N}}$ value determined here is therefore very close to the largest one given in reference 2 . Dorain et al. [2] indicate however that their estimate of $\left\langle r^{-3}\right\rangle$ is quite inaccurate being uncertain by a factor 2 . Moreover, the electronic structures of the investigated species $\left(\mathrm{U}^{3+}, \mathrm{U}\right.$ and $\left.\mathrm{UF}_{6}\right)$ are very different so that chemical effects of a few per cent may be expected for the corresponding effective nuclear magnetic moments. 
The accuracy in our determination of $\mu_{\mathrm{N}}$ is limited by two factors : a marked distortion of the base line by acoustic ringing [6] and a half height line width of $20 \mathrm{kHz}$ of the ${ }^{235} \mathrm{U}$ signal.

In several articles, Ursu et al. [7-9] carried on an indirect study of the nuclear magnetism of ${ }^{235} \mathrm{U}$ through the relaxation of ${ }^{19} \mathrm{~F}$ spins in $\mathrm{UF}_{6}$. These studies showed a dependence of the ${ }^{19} \mathrm{~F}$ relaxation properties upon the isotopic composition of uranium, which was assigned to the relaxation of ${ }^{235} \mathrm{U}$. Although the large value of the ${ }^{235} \mathrm{U}$ line width measured here is an evidence of an efficient quadrupolar relaxation mechanism induced by molecular vibrations, a quantitative comparison seems premature without complementary experiments. Among them an improvement of experimental conditions of observation of the ${ }^{235} \mathrm{U}$ signal (rf. power, pulse sequences) is needed. They might allow, in particular, a practical method for determining the uranium isotope composition, the most abundant one, ${ }^{238} \mathrm{U}$, being devoided of nuclear spin.

\section{References}

[1] Hutchison, C. A., Llewelyn, P. M., Wong, E. and Dorain, P. B., Phys. Rev. 102 (1956) 292.

[2] Dorain, P. B., Hutchison, C. A. and Wong, E., Phys. Rev. 105 (1957) 1307.

[3] Gerstenkorn, S., Luc, P., Bauche-Arnoult, C. and Merle, D., J. Physique 34 (1973) 805.

[4] Rigny, P. and Demortier, A., C. R. Hebd. Séan. Acad. Sci. B 263 (1966) 1408.

[5] Rigny, P. and Virlet, J., J. Chem. Phys. 47 (1967) 4645.

[6] Fuxushima, E. and Roeder, S. B. W., J. Magn. Res. 33 (1979) 199.

[7] Ursu, I., Demco, D. E., Simplaceanu, V., Valcu, N. and Ilie, N., Proceedings of the 18th A.M.P.E.R.E. Congress (Nottingham) 1974, p. 533.

[8] Ursu, I., Demco, D. E., Simplaceanu, V. and Valcu, N., Rev. Roum. Phys. 22 (1977) 705.

[9] Ursu, I., Demco, D. E., Bogdan, M., Daraboni, A., Fitori, P., Grocescu, R. and Valcu, N., Rev. Roum. Phys. 27 (1982) 451. 